\title{
ICAM-1 K469E polymorphism, increased risk of neurocysticercosis occurrence and immunopathological defect
}

\section{Polimorfismo ICAM-1 K469E, aumento do risco de ocorrência de neurocisticercose e defeito imunopatológico}

\section{Dear Editor,}

Neurocysticercosis is an important infectious neuropsychiatric disorder ${ }^{1}$. The infection is caused by a parasite and is common in several tropical countries around the world. The role of immunity of the host for protection against neurocysticercosis is very interesting. The observation by Silva et al. ${ }^{2}$ on interleukin 4 (IL4) and neurocysticercosis is a good example. Here, we would like to draw more attention to a complex immunological defect that can underline increased risk for neurocysticercosis. We would like to discuss the closely-related molecule, intercellular adhesion molecule-1 (ICAM-1). Recently, it was reported that the polymorphism of ICAM-1, the superfamily of immunoglobulin proteins, plays an important role in the susceptibility to neurocysticercosis. In general, ICAM-1 is a required molecule in the T cell immunological response. The ICAM-1 K469E polymorphism is reported for its relationship to the increased risk of neurocysticercosis ${ }^{3,4}$. Here, the authors would like to explain the observation based on the basic principle of quantum molecular biochemistry. In fact, the exchange change in
ICAM-1 K469E is a change of a single amino acid "K (lysine)" to "E (glutamate)". This can result in a molecular weight change from $146.19 \mathrm{~g} / \mathrm{mol}$ to $147.13 \mathrm{~g} / \mathrm{mol}$ or equal to $+0.94 \mathrm{~g} / \mathrm{mol}$, which means it requires more substrate (more ICAM-1) in the biological reaction or it becomes more difficult to complete the biological process. Hence, there is no doubt that having ICAM-1 K469E can result in a defect in the natural immunological protection and "increased risk of the occurrence of neurocysticercosis." This phenomenon is the same as seen in cases of drug resistance in many medical disorders due to a single amino acid change ${ }^{5,6}$. It can also further explain the recent report in by Silva et al. that the "absence of IL-4 induces lower encephalitis'." It has been proven that IL-4 is an important factor stimulating the ICAM-1 expression ${ }^{7}$. Lack of IL-4 can play a similar pathological role to polymorphism, which results in lack of a sufficient amount, or an increased amount of ICAM1 required, for an immunological response to neurocysticercosis.

Beuy Joob $^{1}$, Viroj Wiwanitkit ${ }^{2}$

\section{References}

\footnotetext{
1. Ramirez-Bermudez J, Higuera-Calleja J,

Espinola-Nadurille M, Corona T. Neuropsychiatric disorders in patients with neurocysticercosis. Asia Pac Psychiatry. 2017;9(2). https://doi.org/10.1111/appy.12250

2. Silva HM, Vinaud MC, Lino Júnior RS. Experimental neurocysticercosis: absence of IL-4 induces lower encephalitis. Arq Neuropsiquiatr. 2017;75(2):96-102. https://doi.org/10.1590/0004-282X20160194

3. Arora N, Tripathi S, Sao R, Mondal P, Mishra A, Prasad A. Molecular neuro-pathomechanism of neurocysticercosis: how host genetic factors influence disease susceptibility. Mol Neurobiol. 2017 Jan 13. https://doi.org/10.1007/s12035-016-0373-6
}

\footnotetext{
4. Singh A, Singh AK, Singh SK, Paliwal VK, Gupta RK, Prasad KN. Association of ICAM-1 K469E polymorphism with neurocysticercosis. J Neuroimmunol. 2014;276(1-2):166-71. https://doi.org/10.1016/j.jneuroim.2014.07.018

5. Joob B, Wiwanitkit V.HSD11B1 rs846908 polymorphisms and tacrolimus concentrations: quantum chemical analysis and implication in patients with renal transplantation.J Nephropharmacol. 2016;6(1):19-20

6. Wiwanitkit V. An explanation in nanostructure level based on the view of energy change for G333d mutation relating to drug resistance in HIV-1 reverse transcriptase. Indian J Med Microbiol. 2008;26(2):202-3

7. Berger RB1, Blackwell NM, Lass JH, Diaconu E, Pearlman E.IL-4 and IL-13 regulation of ICAM-1 expression and eosinophil recruitment in Onchocerca volvulus keratitis. Invest Ophthalmol Vis Sci. 2002;43(9):2992-7.
} 